\title{
The Black Sea Mixed Layer Depth Variability and Its Relation to the Basin Dynamics and Atmospheric Forcing
}

\author{
A. A. Kubryakov ${ }^{1, *}$, V. N. Belokopytov ${ }^{I}$, A. G. Zatsepin ${ }^{2}$, \\ S. V. Stanichny ${ }^{I}$ V. B. Piotukh \\ ${ }^{1}$ Marine Hydrophysical Institute of RAS, Sevastopol, Russian Federation \\ ${ }^{2}$ Shirshov Institute of Oceanology, Russian Academy of Sciences, Moscow, Russian Federation \\ *arskubr@ya.ru
}

Purpose. Spatio-temporal variability of the mixed layer depth (MLD) in different areas of the Black Sea in 1985-2017, its relationship with basin dynamics and atmospheric forcing are studied.

Methods and Results. The study is based on the hydrological data archive for 1985-2017 including the measurements of the ship expeditions, the Argo buoys and the moored buoy "Aqalog". Seasonal and interannual variability of the mixed layer depth was determined using the density criterion $(d r=$ $=0.07 \mathrm{~kg} / \mathrm{m}^{3}$ ) between the surface layers and the base of the upper mixed layer.

Conclusions. In January - March, the large-scale and mesoscale dynamics significantly affects the mixed layer depth variability. Minimum monthly average values of the mixed layer depth in winter are observed in the mesoscale cyclonic eddies and in the center of the sea $(20-30 \mathrm{~m})$, the moderate values - on the periphery of the basin $(40-45 \mathrm{~m})$ and the maximum ones - in the mesoscale anticyclones $(60-70 \mathrm{~m})$. Several times the mixed layer depth values exceeding $150 \mathrm{~m}$ were detected in the downwelling areas of the basin. Analysis of the whole period (1985-2017) shows that the mixed layer density was never more than $1015 \mathrm{~kg} / \mathrm{m}^{3}$. This isopycnal limits the maximum possible depth of the upper mixed layer. The impact of wind velocity on the spatial and temporal variability of the mixed layer thickness is the largest in spring and autumn when the seasonal thermocline is weak. It is less important in summer when solar heating stabilizes the upper layer, and in winter when the mixed layer depth is large. Rise of the mixed layer depth in summer is observed in recent years that is associated with rise of the wind speed in a warm period of a year.

Keywords: the Black Sea, mixed layer depth, vertical turbulent mixing, currents, eddies, interannual variability, wind velocity.

Acknowledgements: the data were obtained and processed within the framework of the state order, theme No. 0827-2019-0002; interannual and seasonal variability of MLD was studied at support of the RSF grant 19-77-00029; influence of eddies on MLD was investigated at support of the RFBR grant 17-05-00034, wind impact on MLD variability was analyzed at support of the RFBR grant No.17-05-41102.

For citation: Kubryakov, A.A., Belokopytov, V.N., Zatsepin, A.G., Stanichny, S.V. and Piotukh, V.B., 2019. The Black Sea Mixed Layer Depth Variability and Its Relation to the Basin Dynamics and Atmospheric Forcing. Physical Oceanography, [e-journal] 26(5), pp.397-413. doi:10.22449/1573-160X-2019-5-397-413

DOI: $10.22449 / 1573-160 X-2019-5-397-413$

(C) 2019, A.A. Kubryakov, V.N. Belokopytov, A.G. Zatsepin, S.V. Stanichny, V.B. Piotukh

(C) 2019, Physical Oceanography

\section{Introduction}

The mixed layer (ML) is a layer of water adjacent to the free sea surface, in which the main hydrological parameters of the environment (temperature, salinity and density) are distributed uniformly in vertical direction. The mixed layer depth (MLD) depends on the processes of heat, mass and momentum exchange between the sea and the atmosphere. MLD variability strongly impact on the state of the marine ecosystem, as the vertical involvement of nutrients from the deep layers 
in $\mathrm{ML}$ is the main source of nutrients for phytoplankton in the central part of the Black Sea. The intensity of autumn-winter [1,2] and spring [3, 4] blooming of diatoms directly depends on the vertical mixing processes. Summer blooming of coccolithophorids on an interannual scale correlates with winter cooling and the amount of phosphates involved in ML $[5,6]$. If the MLD significantly exceeds the photic layer thickness, in winter the phytoplankton blooming in the Black Sea can be suppressed [2] due to the general lack of illumination in ML $[1,7]$.

Vertical mixing in the upper layer of the Black Sea is primarily determined by the mechanical effect of the wind friction stress and the buoyancy flow through the sea-atmosphere interface. The strongest mixing is observed in the cold season, when the wind forcing intensifies, and the buoyancy flow associated with the cooling of the sea surface is negative.

Salinity stratification of water prevents the MLD increase. It is very strong in the Black Sea due to the inflow of large rivers into the upper layer and highly saline Mediterranean waters to the underlying layers through the Bosporus. As a result of this, a sharp pycno-halocline is formed at a depth of 50-150 m, which substantially limits vertical mixing with deep water layers.

The pycnocline position in the Black Sea is determined by the complex process of interaction of brackish and saline waters. Its three-dimensional structure (topography) is determined by the basin dynamics. On the basin scale, the dominant cyclonic circulation leads to pycnocline upraise in the cyclonic gyres in the central part of the sea and to its lowering over the continental slope in the Black Sea Rim Current zone (see the review in work ${ }^{1}$ ). The intensity of the large-scale circulation at seasonal and interannual scales is determined by the wind vorticity [8-10]. Vertical movements in mesoscale eddies also lead to a significant change in the position of isopycnic surfaces [11-13]. For example, in anticyclones, the depth of the pycnocline may deepen by $50 \mathrm{~m}$, and in cyclones, the pycnocline can rise by $40 \mathrm{~m}$ relative to unperturbed values [13].

In severe winters, strong atmospheric cooling causes significant cooling and increase of MLD, leading to the strongest renewal or the formation of a cold intermediate layer (CIL) [14-18], which is an important element of the hydrological structure of the Black Sea. At the same time, it was shown in [19] that there is no positive correlation observed between MLD and the cooling on interannual scales in the Black Sea. The reason for this is the impact of basin dynamics in severe winters, the northeastern wind intensifies, which is associated with an increase in the cyclonic vorticity of the wind over the basin $[14,20,21]$. This causes an intensification of the cyclonic circulation and upraise of the main pycnocline (pycno-halocline) in the sea center, which limits the vertical mixing $[14,22]$.

In the warm season, solar heating leads to the appearance of a seasonal thermocline. Thermal stratification suppresses the vertical mixing, and the MLD is usually small in summer [14, 23]. However, a strong wind effect can cause erosion of the seasonal thermocline and a significant increase in the MLD [24].

\footnotetext{
${ }^{1}$ Ivanov, V.A. and Belokopytov, V.N., 2013. Oceanography of the Black Sea. Sevastopol: MHI NAS of Ukraine, $210 \mathrm{p}$.
} 
Such processes also lead to the entrainment of nutrients from the thermocline and CIL and the appearance of abnormal summer phytoplankton blooming in the surface water layer [25].

The study of the Black Sea MLD was carried out in a number of works [14, 20, 26-28], which give estimates of its spatial distribution in different seasons. Various MLD parameters, such as density, temperature and their relationship with winter cooling were studied in [15-17, 26, 27]. The goal of the present work is to study the spatiotemporal variability of MLD in various areas of the Black Sea and investigate its relationship with basin dynamics and atmospheric forcing on the base of long-term archive of hydrological measurements for 1985-2017 period.

\section{Data and Methods}

\subsection{Data}

In the present work, data on the temperature and salinity of the Black Sea for MLD computation was obtained from the following sources:

1) Hydrological measurements of Soviet (Russian), Ukrainian and Turkish vessels from the oceanographic data bank of Marine Hydrophysical Institute from 1985 to 2017 [29];

2) Data from hydrological surveys of $\mathrm{R} / \mathrm{V}$ "Aquanaut" during marine expeditionary work of the Institute of Oceanology of RAS (R/V "Aquanaut") in the northeastern part of the Black Sea in 1997-2008 on the base of high-precision immersion digital $C T D$ probes [16, 17];

3) Measurements of Argo profilers for 2004-2017, taken from the IFREMER archive (ftp://ftp.ifremer.fr/). The instrumental error of the profilers is $0.002{ }^{\circ} \mathrm{C}$ and $0.01 \mathrm{psu}$ [30]. The vertical resolution of these measurements in the upper layer varies from 10 to $1 \mathrm{~m}$ for various buoys;

4) Data of the "Aqualog" profiler at the moored buoy station for 2013-2015 at the IO RAS sub-satellite polygon in the northeastern Black Sea [31].

Temperature and salinity data were vertically interpolated onto a uniform grid with a step of $2 \mathrm{~m}$ and were used to calculate the potential density according to the UNESCO formula.

The ERA-Interim reanalysis data on wind speed at a height of $10 \mathrm{~m}$ were analyzed in the present work. The spatial resolution of the array is $0.75^{\circ}$, the time resolution is 6 hours. The reanalysis data was verified based on a comparison with contact measurements of wind speed over the Black Sea in [32].

The Black Sea level was determined as the sum of level anomalies obtained from the combined measurements of several altimeters (http://www.marine.copernicus.eu) and the average dynamic topography from [33]. Based on this data, daily velocity maps of surface geostrophic currents with a spatial resolution of $1 / 8^{\circ}$ were calculated using geostrophic balance equations.

\subsection{The MLD determination method}

Both thermal and haline stratification have a significant effect on mixing in the Black Sea in different seasons. Therefore, the density criterion was used to determine MLD: it was calculated as the depth at which the potential water density is higher than its potential density at the upper level of measurements by a given value $d r$ [28]. Based on the empirical approach, a value of $d r$ equal to $0.07 \mathrm{~kg} / \mathrm{m}^{3}$ 
was chosen. For an accurate MLD estimate, profiles with less than five measurements in the 0-50 m layer were excluded from the analysis. In addition, in the warm season, profiles with less than two measurements in the $0-10 \mathrm{~m}$ layer were also excluded. It should be noted that the vertical resolution in this layer was often insufficient to determine MLD in the warm season, when the real MLD values were less than $5 \mathrm{~m}$. Therefore, in the indicated period, the calculated MLD values can be slightly overestimated. In total, more than 32,000 MLD estimates on the Black Sea were obtained for 1985-2017.
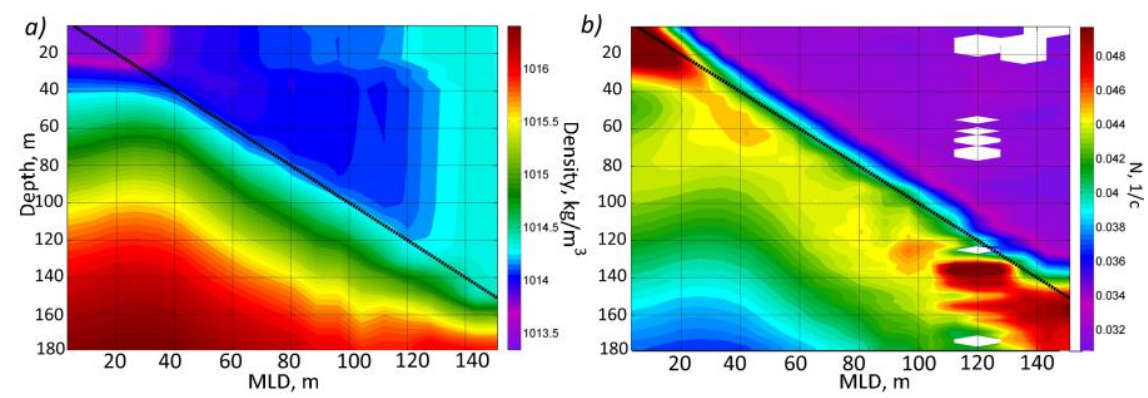

F i g. 1. Composite (average) vertical structure of potential density, $\mathrm{kg} / \mathrm{m}^{3}(a)$ and the Väisäl - Brent frequency, $1 / \mathrm{s}(b)$ for different intervals of the MLD values

To check the selected criterion the Fig. 1 shows the composite vertical structure of the potential density and the Väisäl - Brent frequency for different MLD values. To calculate the diagram (Fig. 1, a), all density profiles for each interval of MLD (for example, 20-30 m) were averaged; the result was plotted in color. The figure shows that above MLD (black diagonal line) determined using the density criterion, the density is relatively uniform, and the Väisäl - Brent frequency is minimal and close to zero. This means that the overlying water layer is vertically mixed, and illustrates the suitability of the selected criterion for determining the MLD in the Black Sea. Note that the value of $d r$, chosen as a criterion, equal to $0.07 \mathrm{~kg} / \mathrm{m}^{3}$, is less than that selected in [28] $\left(0.125 \mathrm{~kg} / \mathrm{m}^{3}\right)$. Therefore, MLD estimates obtained in [28] will be somewhat higher than in the present work.

\section{The MLD Time Variability}

Fig. 2, $a$ shows the seasonal MLD variability, spatially averaged over various parts of the water area: in the central part of the sea (depths of more than $2000 \mathrm{~m}$ ) and in the continental slope area (depths of 100-1500 m). The seasonal MLD variability is primarily determined by the heat fluxes between the ocean and the atmosphere. With an increase in the incident short-wave radiation at the end of March - April, a seasonal thermocline begins to form in the upper layer at depths of 10-20 m (Fig. 3, a). Thermal heating causes an increase of the water stratification in the upper layer, leading to a sharp MLD decrease. The graph of the temperature dependence of MLD (Fig. 2, b) on a $5 \mathrm{~m}$ horizon shows that with an increase in the temperature of the upper layer from 8 to $10-12{ }^{\circ} \mathrm{C}$, i.e., only 2-4 ${ }^{\circ} \mathrm{C}$, MLD decreases two times: from 30-40 to 10-20 m. 

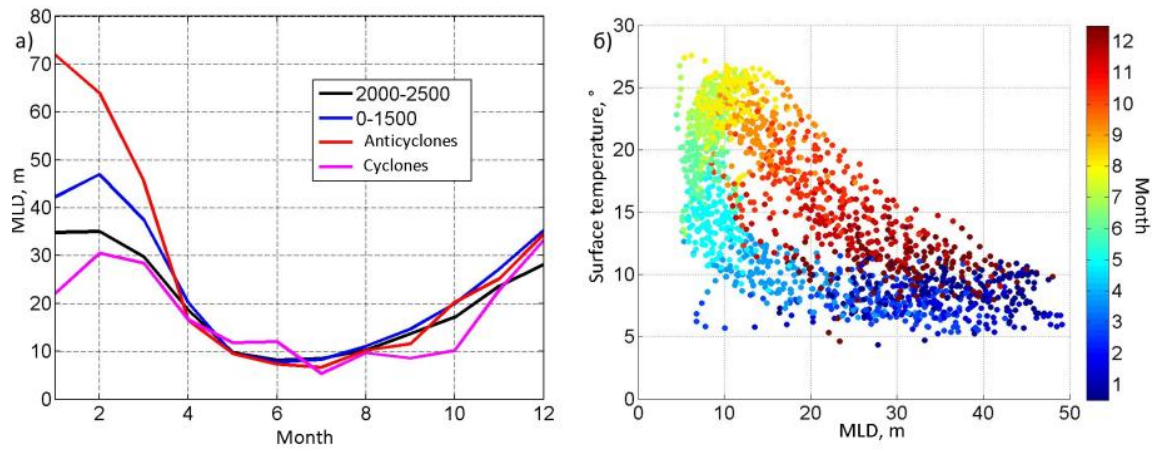

F i g. 2. Seasonal variability of MLD in the central part of the sea (black line), over the continental slope (red line), in the cyclonic eddies (magenta line) (a); dependence of MLD in the sea center upon the temperature on depth $5 \mathrm{~m}(b)$

With a further temperature increase from 12 to $22{ }^{\circ} \mathrm{C}$ in the spring-summer period, MLD changes only slightly (Fig. 2, b). In the summer period, from May to September, on average $t$ is equal to 5-10 m. The periodic effect of wind and waves causes mixing in the upper layer of the sea, therefore, the monthly average MLD values rarely drop below $5 \mathrm{~m}$, even during the maximum summer heating.
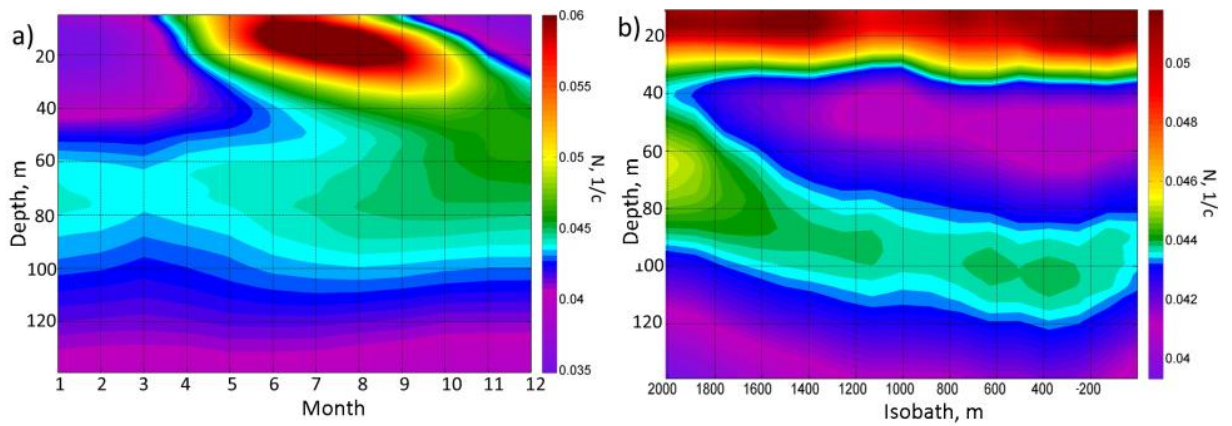

F i g. 3. Seasonal variability of the Väisäl - Brent frequency (1/s) in the central part of the sea (depth exceeding $2000 \mathrm{~m})(a)$; average distribution of the Väisäl - Brent frequency (1/s) for different isobaths of the Black Sea $(b)$

The maximum density gradient from April to August is observed at a depth of 5-15 m (Fig. 3, a).

The heat flux decrease at the end of August leads to a gradual deepening of the thermocline in the autumn period. From September to January, MLD in the sea center almost linearly depends on the surface temperature (Fig. 2, b). The vertical diagram of seasonal variability of the Väisäl - Brent frequency (Fig. 3, a) shows that the seasonal thermocline determines the stratification of the upper layer $(0-40 \mathrm{~m})$ from April to November. At this time, the average MLD values do not exceed $25 \mathrm{~m}$. In December - January, the seasonal thermocline completely collapses, and the main pycno-halocline starts to play the main role in preventing vertical mixing (Fig. 3,a). 


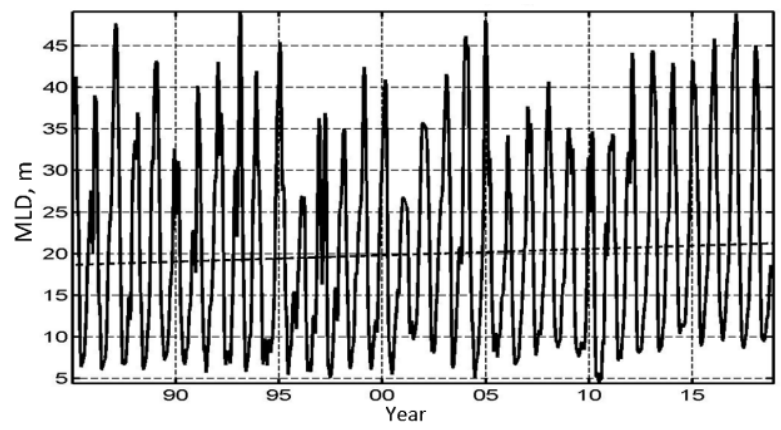

F i g. 4. Interannual variability of MLD in the central part of the sea (90-day filtration by the moving average)

The interannual variability of MLD calculated on the basis of the entire data array is shown in Fig. 4. For the calculation, the data for the central part of the sea were averaged for each month, then the series was smoothed using a moving average with a window size of 90 days. Some features of the interannual move should be noted. The maximum MLD values were repeated with approximately a 10-year periodicity in 1993-1995, 2005 and 2015-2017. Such periodicity can be associated with 10-year fluctuations in the sea surface temperature field [34]. The long-term MLD increase in the warm season is also observed. Until the 2000s, MLD during the summer period was 6-8 $\mathrm{m}$, and after 2010 its values exceeded $10 \mathrm{~m}$ on average. Such an increase is probably associated with the wind intensity increase (see Section 5).

\section{Winter Distribution of MLD and its Relation to Water Dynamics}

In winter, MLD distribution over the basin area is characterized by significant spatial variability (Fig. 5, a). This variability is caused by the difference in the depth of the main pycnocline position in various parts of the basin. Due to the general cyclonic circulation, the pycnocline is elevated in the central part of the sea and lowered on its periphery. The spatial distribution of the Väisäl - Brent frequency values on the diagram shows (see Fig. 3, $b$ ) that in the deep part of the sea (beyond the isobath of $2000 \mathrm{~m}$ ) the pycnocline is located at a depth of $40-90 \mathrm{~m}$ and in the upper part of the continental slope $(H>500 \mathrm{~m}) 40 \mathrm{~m}$ lower - at a depth of 80-120 m. Such topography of the main pycnocline leads to the fact that winter mixing, caused by cooling of the waters and wind exposure, affects a deeper layer at the basin periphery. Therefore, in the coldest period of the year, from January to March (see Fig. 2, $a ; 5, a$ ), MLD in the sea center is much lower than in the continental slope area [14]. In the central part of the sea, the average MLD values in January - March are 35, 35 and $30 \mathrm{~m}$ (see Fig. 2, a), while in the continental slope area (isobaths $200-1500 \mathrm{~m}$ ) they are on 7-10 $\mathrm{m}$ larger and are 42,47 and $40 \mathrm{~m}$, respectively.

The maximum MLD values are observed in the northwestern part of the sea, where in February - March they exceed $50 \mathrm{~m}$ (Fig. 5, a). There are at least two possible reasons for the formation of the maximum MLD in this area. Firstly, the area is adjacent to the wide north-western shelf of the basin. In winter, the waters are significantly cooled in shallow areas of the northwestern shelf and 
mixed almost to the bottom. If, as a result of cooling, their density exceeds the density of water in the central part of the sea, then they flow down the slope of the basin in the density flow regime and contribute to the MLD increase in areas adjacent to the shelf $[35,36]$.

Secondly, the northwestern part of the sea is characterized by intense mesoscale eddy dynamics. Here, the formation and stationing of the large Sevastopol anticyclone is observed. Downward movements in anticyclones lead to an additional lowering of the pycnocline and its maximum deepening. Convergence in anticyclones leads to the surface water accumulation, which causes an increase of cold storage in their cores to maximum values and intensive formation of CIL waters [11, 13, 23, 36, 37]. The accumulation of surface waters with the same properties and the lowering of the main pycnocline contribute to the weakening of the upper layer stratification in anticyclones [13]. The authors of [36] show that MLD in the Sevastopol eddy can reach high values excessing 50-60 m.

a) Cold period of year
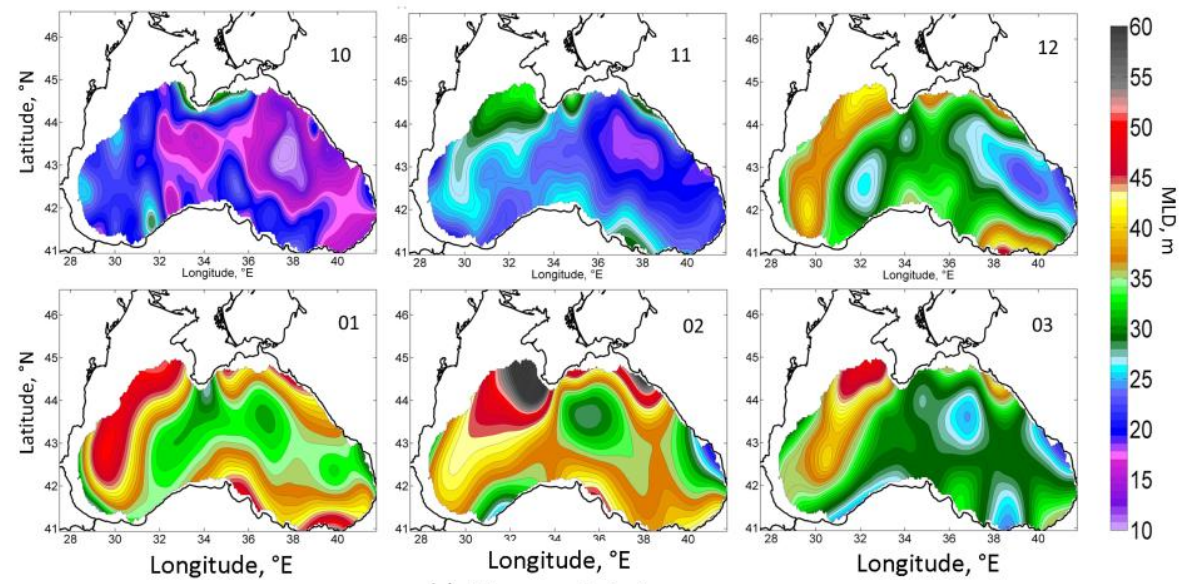

b) Warm period of year
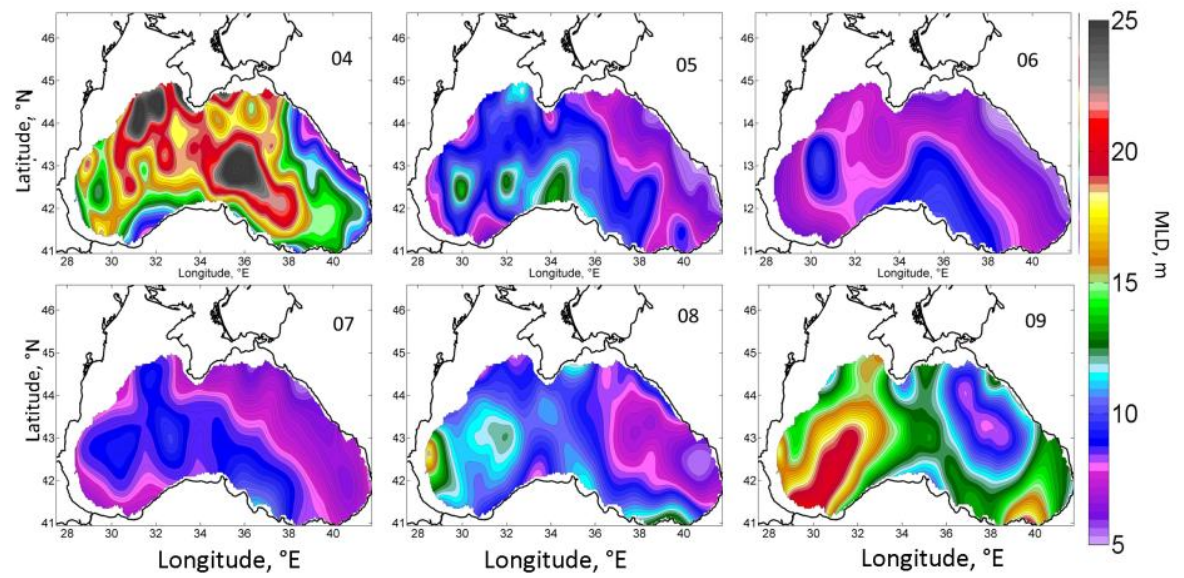

F i g. 5. Spatial distribution of MLD: $a$-in a cold period (October - March); $b$ - in a warm period (April - September) 
In winter, the RMS deviation for the MLD values is quite large and is $10 \mathrm{~m}$ for the central part of the sea and $15 \mathrm{~m}$ for the continental slope area. Such variability is associated with dynamic processes - the intensity of the eddy and large-scale dynamics in the basin.

To study the effect of eddies on MLD, the method of composite analysis of altimetry and hydrological data was used [13]. Mesoscale eddies were identified by geostrophic velocity data obtained from measurements of satellite altimeters. For this purpose, the "winding angle" method based on the allocation of closed streamlines in the velocity field was used [38]. The eddy sign was determined by the average value of the vorticity in it. The details of this algorithm, the results of its work on determining the characteristics of the Black Sea eddies and its validation are given in $[39,40]$. Then, only those hydrological profiles that were in intense mesoscale eddies with an orbital velocity of more than $15 \mathrm{~cm} / \mathrm{s}$ were selected. In total, 1,290 profiles were distinguished in anticyclones and 230 - in cyclones. Based on the profiles selected, the seasonal variability of MLD in the eddies of different signs was determined.

According to Fig. 2, a, mesoscale variability affects MLD in winter, when vertical mixing is limited by the main pycnocline. The lowering of isopycnals in anticyclones leads to the MLD increase and the rise in cyclones leads to its decrease. In cyclonic eddies MLD is minimal and amounts to only $20 \mathrm{~m}$ in January and $30 \mathrm{~m}$ in February - March. In anticyclones the average MLD is maximum: in January it reaches $70 \mathrm{~m}$, in February - $65 \mathrm{~m}$ and in March - $50 \mathrm{~m}$. A sharp jump in MLD from 35 to $75 \mathrm{~m}$ in anticyclonic eddies is observed from December to January. In December, the seasonal thermocline erodes completely (Fig. 3, $a$ ), and the main pycnocline begins to play a decisive role in limiting the vertical mixing. Since the main pycnocline is lowered in anticyclones, in January MLD in these eddies sharply increases. The deepening of the pycnocline is determined by intensity of the eddies [13] and it can be expected that in the most intense anticyclones MLD can reach even greater values.

To determine the areas of intensive mixing, measurement points at which MLD in the study period exceeded 70 and 100 m were marked in Fig. 6. Fig. 6, a shows its highest values are observed only in the areas of the continental slope of the basin, where the pycnocline is deepened. MLD more than $100 \mathrm{~m}$ was most often observed in the northwestern part of the sea. Downward movements in the Sevastopol anticyclone and slope convection increase the intensity of vertical mixing in this area. In addition, the depth of the ML lower boundary exceeding $100 \mathrm{~m}$ was observed eight times in the northeastern part of the sea in the Gelendzhik region according to the "Aqualog" profiler measurements, once in the southwestern part of the sea near the Bosporus and twice in the Anatolian coast. It should be noted that this distribution of high MLD values is partly due to the spatial heterogeneity of the number of measurements - the Marine Hydrophysical Institute contains more data for the northern part of the sea off the coast of Crimea, and "Aqualog" profiler provides numerous regular measurements with a frequency of 6 hours in the northeast parts of the sea. 


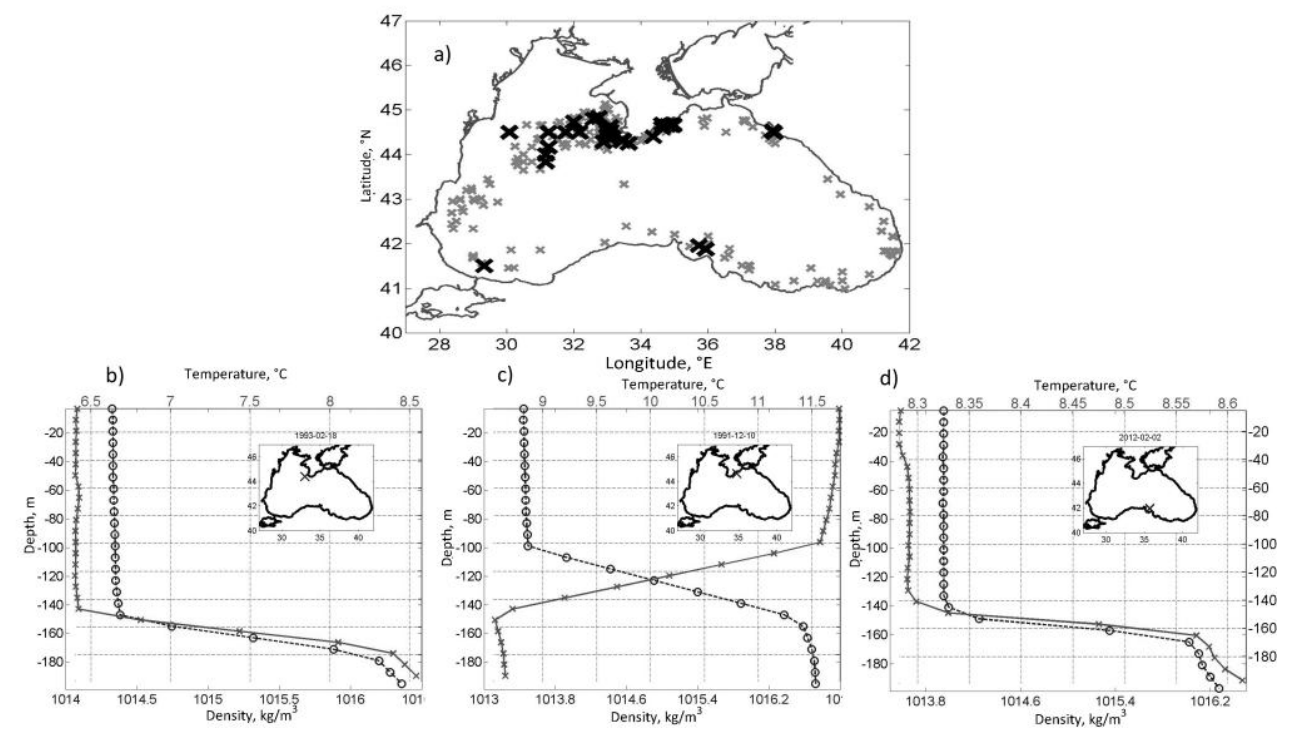

F i g. 6. Location of the points were the anomalously high values of MLD were observed (a); density (circles) and salinity (crosses) profiles in the measurement points where MLD exceeds $100 \mathrm{~m}$ : in the northwestern part of the sea on February 18, $1993(b)$; nearby the South Coast of the Crimea on December 10, $1991(c)$; in the southern part of the sea on February 2, $2012(d)$

An example of a temperature and density profile in the Sevastopol eddy region for February 18, 1993 is shown in Fig. 6, $b$. That year the winter was severe and MLD temperature reached extremely low values $\left(6.5^{\circ} \mathrm{C}\right)$. The density profile shows that the upper layer is mixed down to the depths exceeding $150 \mathrm{~m}$. Nevertheless, due to the low salinity values (18 psu), ML density does not exceed $1014.4 \mathrm{~kg} / \mathrm{m}^{3}$, i.e. it is relatively low for such a mixing depth. This indicates the accumulation of fresh water and the lowering of pycnocline in this area, which is probably due to the Sevastopol anticyclone activity. A sharp winter cooling led to the formation of ML of large thickness in this eddy.

On the graph for December 10, 1991 (Fig. 6, c) near the Southern Coast of Crimea, the values of MLD thickness are also high - more than $100 \mathrm{~m}$. However, the MLD was quite warm: its temperature was more than $8.8^{\circ} \mathrm{C}$ and density was less than $1013.6 \mathrm{~kg} / \mathrm{m}^{3}$. In this case, the main cause for the formation of a deep MLD was the dynamics of waters (convergence in the upper layer and lowering of the pycnocline), not the buoyancy fluxes.

In the southern part of the basin, large values of MLD thickness were recorded by the modern measurements of Argo buoys in the winter of 2012, which was also cold. On the profile for February 2, 2012 (Fig. 6, d) it can be seen that the MLD thickness in the southern part of the sea reached extreme values for the Black Sea $140 \mathrm{~m}$. Down to $140 \mathrm{~m}$ depth the salinity was $18.2 \mathrm{psu}$, then sharply increased by more than 2 psu to the values of $20.7 \mathrm{psu}$ at $\sim 160 \mathrm{~m}$ depths. Such a difference indicates an extremely sharp halocline which begins immediately at the MLD lower boundary and limits vertical mixing. At the same time, the MLD temperature was quite high - about $8.3^{\circ} \mathrm{C}$, i.e. it contained relatively warm surface water and the formation of a new CIL (with a temperature lower than $8^{\circ} \mathrm{C}$ ) did not occur. 
Large MLD can negatively affect the biological productivity of the basin, since the depth of the euphotic layer in winter is much smaller ( $50 \mathrm{~m})$ [4]. Therefore, in winter in the zones of the most intense downward movements on the continental slope and in the anticyclones a decrease in the chlorophyll $a$ concentration can be expected $[1,7]$.

As follows from Fig. 1, $a$, an extremely large ML thickness (more than $70 \mathrm{~m}$ ) is observed only in the case of dynamic deepening of the main pycnocline $\left(1015 \mathrm{~kg} / \mathrm{m}^{3}\right)$, i.e. only in the areas of strong downward movements - in the downwelling zones in the region of the continental slope or in intense anticyclonic eddies. We also note that with an increase in the ML thickness (more than $100 \mathrm{~m}$ ), the stratification in the underlying layers sharply increases (see Fig. 1,b). This is due to the "compression" of isopycnic lines that occurs as a result of their deepening in the upper layer [13]. Thus, even at extreme values of MLD thickness vertical mixing is not able to overcome the pycno-halocline barrier and bring the underlying water into the upper layer. The maximum recorded potential density of MLD was $1014.97 \mathrm{~kg} / \mathrm{m}^{3}$. In total, density values exceeding $1014.9 \mathrm{~kg} / \mathrm{m}^{3}$ were 19 , and exceeding $1014.8 \mathrm{~kg} / \mathrm{m}^{3}-50$, which is less than $0.1 \%$ of the entire array. Most of these high values were observed in the center of the eastern cyclonic gyre during the surveys in cold February 1991, when the surface temperature was below $5^{\circ} \mathrm{C}$.

Consequently, the underlying layers with a higher density (more than $1015 \mathrm{~kg} / \mathrm{m}^{3}$ ) cannot be in direct contact with the atmosphere, and the oxygen supply to them is limited by sharp density stratification. The oxygen penetration into the lower layers is possible only as a result of diapycnic processes - turbulent diffusion, associated, for example, due to a vertical shear in the Rim Current [41]. Therefore, a sharp pycno-halocline, which limits the oxygen supply to the deeper sea layers with a higher density, is one of the main causes for the existence of a hydrogen sulfide zone in the basin [42].
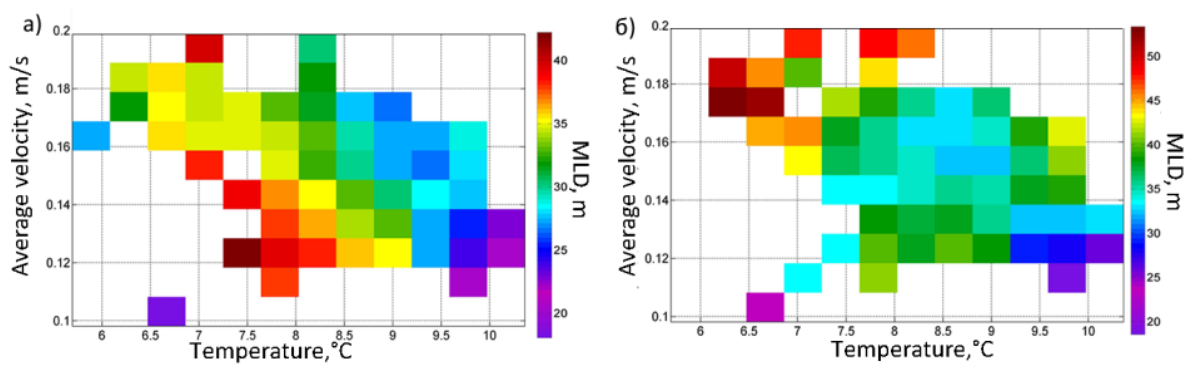

F i g. 7. Dependence of MLD in the sea central part $(a)$ and on its periphery $(b)$ upon the basinaverage altimetry-derived current velocity and surface temperature

The MLD thickness in winter is closely related to the position of the main pycnocline, which, in its turn, is affected by the dynamics of the basin. As mentioned above, during the intensification of the large-scale cyclonic circulation in the Black Sea, the pycnocline rises in the center of the sea and lowers on the periphery. Thus, a more intense circulation under the same atmospheric effects should lead to the ML thickening above the continental slope and its thinning in the center of the sea. This relation is visible in Fig. 7, which shows 406 PHYSICAL OCEANOGRAPHY VOL.26 ISS. 5 (2019) 
the dependence of the MLD on the basin-averaged current velocity and surface temperature. With an increase in the average current velocity from 0.10 to $0.18 \mathrm{~m} / \mathrm{s}$, the MLD in the center of the sea decreases from $35-40 \mathrm{~m}$ to $25-35 \mathrm{~m}$ at a surface temperature of $7-9{ }^{\circ} \mathrm{C}$. At the same time, with an increase in the current velocity at the periphery of the sea the MLD increases from 35 to $50 \mathrm{~m}$ at $7-8{ }^{\circ} \mathrm{C}$ temperature, and from 25 to $40 \mathrm{~m}$ at $9-10{ }^{\circ} \mathrm{C}$ temperature. Note that at the lowest current velocity on the continental slope this relationship is broken: the MLD grows with a decrease in the current velocity from 0.14 to $0.12 \mathrm{~m} / \mathrm{s}$. The weakening of the Rim Current in this region intensifies the formation of anticyclones. The deepening of isopycnic lines in them can lead to an increase, rather than a decrease, of MLD.

\section{MLD thickness in the warm period of the year and its relation with the wind velocity}

In the warm season the average values of MLD are 5-20 m (Fig. 5, b; 8, a). The minimum values of MLD are observed during the period of maximum heating in June - July, when they are on average less than $10 \mathrm{~m}$. The position of seasonal thermocline is determined by the balance of buoyancy and turbulent energy fluxes near the sea - atmosphere boundary. In this case, a positive buoyancy flux is provided mainly by the flux of solar short-wave radiation. Since the latter is approximately uniform in the basin water area, the average values of the MLD thickness at the periphery and in the center of the sea practically coincide and do not exceed $10 \mathrm{~m}$ (see Fig. 2, a). RMS for estimating the MLD thickness in summer is also small and amounts to $2-3 \mathrm{~m}$

At the same time, the spatial distribution of MLD thickness in the springautumn period is characterized by the minimum values in the eastern part and large values in the western part of the basin (Fig. 8, a). Such a distribution is associated with spatial features of the wind velocity field above the basin (Fig. 8, b) [43]. The prevailing wind direction above the Black Sea is the northeastern one. The high Caucasus Mountains form a zone of wind shadow in the southeastern region of the basin. In this area average wind velocity does not exceed $4 \mathrm{~m} / \mathrm{s}$. The maximum wind velocity (more than $6 \mathrm{~m} / \mathrm{s}$ ) is observed in the southwestern part of the sea. The positive influx of buoyancy due to the runoff of the Caucasian rivers and significant precipitation in the southeastern part of the sea are also likely to contribute to a decrease in the MLD thickness in this part of the sea.

Wind action is the most significant cause of variability in the MLD during the warm season. The diagram of the dependence of MLD thickness on the basinaveraged wind velocity and surface temperature, presented in Fig. 8, c, reflects the features of the relationship between thermal stratification and wind mixing. It is clearly seen that in $10-25{ }^{\circ} \mathrm{C}$ temperature range the MLD thickness significantly grows with the increase of average wind velocity. For example, at $15{ }^{\circ} \mathrm{C}$ temperature the average MLD thickness throughout the basin increases by 2-3 times: from $5-10$ to $25 \mathrm{~m}$ with wind velocity increase from 4 to $8 \mathrm{~m} / \mathrm{s}$. At high temperatures the MLD thickness is less sensitive to the wind velocity variation. At $T=24{ }^{\circ} \mathrm{C}$, a similar increase in wind velocity from 4 to $8 \mathrm{~m} / \mathrm{s} \mathrm{leads}$ to MLD increase from $5-10$ to $15 \mathrm{~m}$, since strong thermal stratification prevents turbulent involvement determined by wind action. 

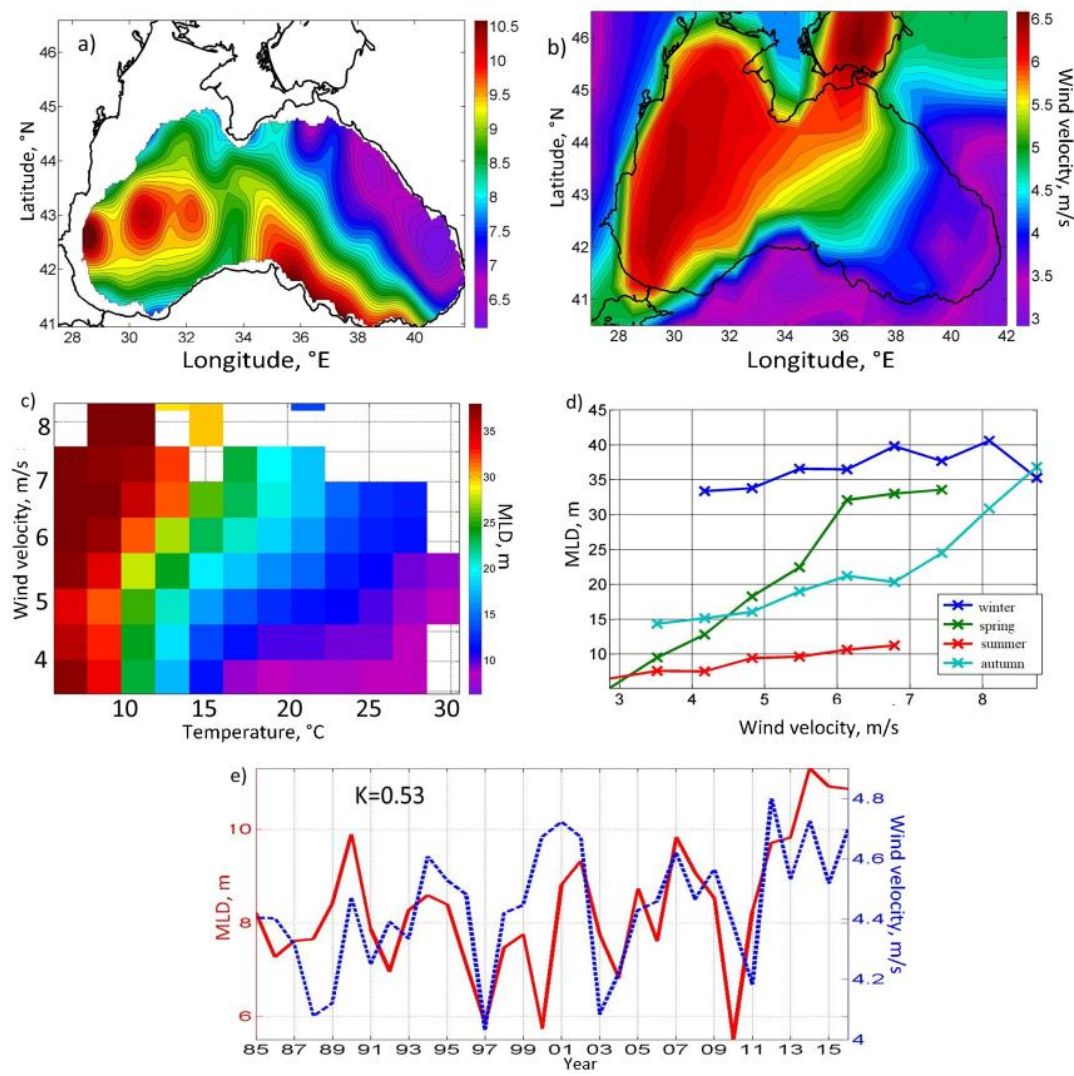

F i g. 8. Spatial distribution of the basin-average $\operatorname{MLD}(a)$ and the wind speed $(b)$ in a summer period; diagram of dependence of the basin-average MLD on the basin-average wind speed and surface temperature $(c)$; dependence of the basin-average MLD on the average wind speed in different seasons $(d)$; interannual variability of the basin-average MLD and the average wind speed over the Black Sea in a summer period $(e)$

In Fig. 8, $d$ the dependence of MLD thickness on the wind velocity in different seasons is shown. As can be seen, the most significant changes in the MLD thickness with an increase in wind velocity are observed in the spring and autumn periods. An increase in the average wind velocity from 4 to $8 \mathrm{~m} / \mathrm{s}$ in spring leads to the growth of MLD thickness from 10 to $30 \mathrm{~m}$. At this time of the year, the seasonal thermocline is just beginning to form and is still weak, therefore, a strong wind effect can quickly destroy it and mix the upper layer to more high (winter) values of MLD thickness. In autumn, when the sea cools, the thermocline weakens. Strong autumn storms can destroy it to a large extent in a few days and make its state close to the winter one [24]. In the autumn and spring the RMS of average MLD thickness is 6-10 m. MLD thickness is much less sensitive to the wind effect in the summer. During this period, RMS of the MLD thickness does not exceed 2-3 m, as solar heating increases the stratification of the upper layer and the thermocline is the most developed. A weak MLD dependence on the wind is also observed in winter, when the main halocline prevents vertical mixing even under stormy conditions. Nevertheless, in the central regions of the sea, where 
the main pycnocline is raised as close to the surface as possible, convective-wind mixing should cause its erosion and salinization of ML waters. According to the hypothesis of I. M. Ovchinnikov and Yu. I. Popov [44], the cooled and salinized ML in the central parts of cyclonic gyres is the main water source of newly formed CIL in the Black Sea.

For the summer period, the interannual variability of MLD and wind velocity above the basin has a positive correlation with 0.54 coefficient (Fig. 8,e). In the years of the strongest summer wind action (velocity of more than $4 \mathrm{~m} / \mathrm{s}$ ) MLD exceeded $10 \mathrm{~m}$, in years with weak summer winds it was less than $8 \mathrm{~m}$. Note that due to the relatively low vertical resolution of measurements in the upper layer, the real values of MLD may be slightly lower. In the summer period the maximum values of MLD were observed in 1990, 1994, 2001 and 2013-2016. In Fig. 8, $c$ one can also note a tendency toward an increase in MLD in recent years (2013-2016) compared with 2000-2012. This tendency is most likely related to the increase in the number of storm events in the summer period noted in [45] during these years. For example, in June 2001 a severe storm occurred in the Black Sea. Its effect caused a decrease in the average monthly temperature by $3{ }^{\circ} \mathrm{C}$ compared with the climatic value ( 18 and $21^{\circ} \mathrm{C}$, respectively). A number of severe storms were also noted in August 2015 [25]. These events are also visible on the graph of MLD thickness variability. An increase in the intensity of storms in the summer can lead to the entrainment of nutrients into the surface layer and the occurrence of intense bloom of phytoplankton in the warm season [25], significantly affecting the functioning of the Black Sea ecosystem.

\section{Conclusions}

In this work, based on the use of a large array of hydrological measurements (more than 30 thousand), the analysis of MLD seasonal and interannual variability in the Black Sea was carried out. In the cold season, when the main pycnohalocline limits vertical mixing, the dynamics of the basin water have a significant effect on the MLD. In the central regions of the sea, where the pycnocline is elevated, the MLD thickness from January to March is $30-35 \mathrm{~m}$, which is $7-15 \mathrm{~m}$ less than in the areas of the continental slope of the basin where the pycnocline is deep. The maximum MLD values are observed in intense mesoscale anticyclonic eddies, where in winter they reach, on average, 65-70 m, and the minimum - in cyclonic mesoscale eddies $(25-30 \mathrm{~m})$. In a number of cases, extremely high MLD for the Black Sea, reaching 100 and even $150 \mathrm{~m}$, were recorded. All these cases belonged to the periphery of the basin (pycnocline lowering zone).

On the basis of a composite analysis of the MLD thickness and its density structure, it is shown that even with the above mentioned high values of the MLD the density of its waters does not exceed $1015 \mathrm{~kg} / \mathrm{m}^{3}$, i.e. the waters of the main pycnocline, with the exception of its upper part, are not entrained in the mixing and do not interact with the atmosphere.

During the heating period, the mechanical effect of the wind is the main factor causing the of MLD thickness variability. Light winds in the eastern part of the sea and strong winds in the southwestern part lead to a corresponding spatial distribution of MLD with a maximum in the west and a minimum in the east of the basin. 
The dependences between the MLD, wind velocity and sea surface temperature are obtained in the work. Wind effect is most significant in the spring and autumn periods of weakened stratification of the upper layer waters and is less pronounced in the summer with a sharp seasonal thermocline during the period of maximum heating. At interannual scales a rather pronounced positive correlation between the MLD thickness and the wind velocity in summer is observed. In recent years (2013-2016) an increase in summer values of MLD associated with the intensification of summer storms [45] has been observed.

Stratification is the main factor weakening the vertical mixing intensity in a particular basin of the World Ocean. The rapid global warming observed in the past few decades should lead to a corresponding decrease in MLD. Recent studies show that the haline stratification, which determines the thickness of the main pycnocline in the Black Sea, is also undergoing strong changes [46]. In 1980-2010 decrease of salinity of the upper layer was noted, which should lead to a weakening of the vertical mixing (see works ${ }^{1,2}$, and also [47]). However, since 2015 a rather intensive increase in the upper layer salinity has been observed, partially compensating the thermal contribution to the density stratification of the Black Sea waters $[15,45]$. The study of the Black Sea stratification variability and the effect of changes in temperature and salinity of the upper layer water on it is an important problem that the authors plan to solve in future works.

\section{REFERENCES}

1. Mikaelyan, A.S., Chasovnikov, V.K., Kubryakov, A.A. and Stanichny, S.V., 2017. Phenology and Drivers of the Winter-Spring Phytoplankton Bloom in the Open Black Sea: The Application of Sverdrup's Hypothesis and its Refinements. Progress in Oceanography, [ejournal] 151, pp. 163-176. https://doi.org/10.1016/j.pocean.2016.12.006

2. Mikaelyan, A.S., Kubryakov, A.A., Silkin, V.A., Pautova, L.A. and Chasovnikov, V.K., 2018. Regional Climate and Patterns of Phytoplankton Annual Succession in the Open Waters of the Black Sea. Deep Sea Research Part I: Oceanographic Research Papers, [e-journal] 142, pp. 44-57. doi:10.1016/j.dsr.2018.08.001

3. Finenko, Z.Z., Suslin, V.V. and Kovaleva, I.V., 2014. Seasonal and Long-Term Dynamics of the Chlorophyll Concentration in the Black Sea according to Satellite Observations. Oceanology, [e-journal] 54(5), pp. 596-605. https://doi.org/10.1134/S0001437014050063

4. Vedernikov, V.I. and Demidov, A.B., 1997. Vertical Distribution of Primary Production and Chlorophyll during Different Seasons in Deep Regions of the Black Sea. Oceanology, 37(3), pp. 376-384.

5. Mikaelyan, A.S., Silkin, V.A. and Pautova, L.A., 2011. Coccolithophorids in the Black Sea: Their Interannual and Long-Term Changes. Oceanology, [e-journal] 51(1), pp. 39-48. https://doi.org/10.1134/S0001437011010127

6. Silkin, V.A., Pautova, L.A., Giordano, M., Chasovnikov, V.K., Vostokov, S.V., Podymov, O.I., Pakhomova, S.V. and Moskalenko, L.V., 2019. Drivers of Phytoplankton Blooms in the Northeastern Black Sea. Marine Pollution Bulletin, [e-journal] 138, pp. 274-284. https://doi.org/10.1016/j.marpolbul.2018.11.042

7. Sverdrup, H.U., 1953. On Conditions for the Vernal Blooming of Phytoplankton. ICES Journal of Marine Science, [e-journal] 18(3), pp. 287-295. https://doi.org/10.1093/icesjms/18.3.287

8. Zatsepin, A.G., Kremenetskiy, V.V., Poyarkov, S.G., Ratner, Yu.B. and Stanichny, S.V., 1991. Influence of Wind Field on Water Circulation in the Black Sea. In: A. G. Zatsepin and M.V. Flint, eds., 1991. Multidisciplinary Investigations of the Northeast Part of the Black Sea. Moscow: Nauka, pp. 91-105 (in Russian). 
9. Korotaev, G.K., Saenko, O.A. and Koblinsky, C.J., 2001. Satellite Altimetry Observations of the Black Sea Level. Journal of Geophysical Research: Oceans, [e-journal] 106(C1), pp. 917933. https://doi.org/10.1029/2000JC900120

10. Kubryakov, A.A., Stanichny, S.V., Zatsepin, A.G., Kremenetskiy, V.V., 2016. Long-Term Variations of the Black Sea Dynamics and Their Impact on the Marine Ecosystem. Journal of Marine Systems, [e-journal] 163, pp. 80-94. https://doi.org/10.1016/j.jmarsys.2016.06.006

11. Latun, V.S., 1990. Anticyclonic Eddies in the Black Sea in the Summer of 1984. Soviet Journal of Physical Oceanography, [e-journal] 1(4), pp. 279-286. https://doi.org/10.1007/BF02197397

12. Zatsepin, A.G., Ginzburg, A.I., Kostianoy, A.G., Kremenetskiy, V.V., Krivosheya, V.G., Stanichny, S.V. and Poulain, P.-M., 2003. Observations of Black Sea Mesoscale Eddies and Associated Horizontal Mixing. Journal of Geophysical Research: Oceans, [e-journal] 108(C8), 3246. https://doi.org/10.1029/2002JC001390

13. Kubryakov, A.A., Bagaev, A.V., Stanichny, S.V. and Belokopytov, V.N., 2018. Thermohaline Structure, Transport and Evolution of the Black Sea Eddies from Hydrological and Satellite Data. Progress in Oceanography, [e-journal] 167, pp. 44-63. https://doi.org/10.1016/j.pocean.2018.07.007

14. Titov, V.B., 2004. Integral Effect of Thermal and Dynamical Atmospheric Factors on the Hydrological Structure of the Black Sea Waters. Oceanology, 44(6), pp. 783-788.

15. Belokopytov, V.N., 2011. Interannual Variations of the Renewal of Waters of the Cold Intermediate Layer in the Black Sea for the Last Decades. Physical Oceanography, [ejournal] 20(5), pp. 347-355. https://doi.org/10.1007/s11110-011-9090-X

16. Piotukh, V.B., Zatsepin, A.G., Kazmin, A.S., Yakubenko, V.G., Stanichny, S.V. and Ratner, Yu.B., 2009. Impact of the Winter Atmospheric Forcing on the Variability of the Active Layer's Thermohaline Structure in the Black Sea. Sovremennye Problemy Distantsionnogo Zondirovaniya Zemli iz Kosmosa, 6(1), pp. 442-450 (in Russian).

17. Piotukh, V.B., Zatsepin, A.G., Kazmin, A.S. and Yakubenko, V.G., 2011. Impact of the Winter Cooling on the Variability of the Thermohaline Characteristics of the Active Layer in the Black Sea. Oceanology, [e-journal] 51(2), pp. 221-230. https://doi.org/10.1134/S0001437011020123

18. Korotaev, G.K., Knysh, V.V. and Kubryakov, A.I., 2014. Study of Formation Process of Cold Intermediate Layer Based on Reanalysis of Black Sea Hydrophysical Fields for 1971-1993. Izvestiya, Atmospheric and Oceanic Physics, [e-journal] 50(1), pp. 35-48. https://doi.org/10.1134/S0001433813060108

19. Titov, V.B., 2004. Formation of the Upper Convective Layer and the Cold Intermediate Layer in the Black Sea in Relation to the Winter Severity. Oceanology, 44(3), pp. 327-330.

20. Titov, V.B., 2003. On the Correlation between Seasonal Atmospheric Conditions and Parameters of the Hydrological Water Structure in the Northeastern Black Sea. Oceanology, 43(3), pp. 325-332.

21. Shokurov, M.V. and Shokurova, I.G., 2017. Wind Stress Curl over the Black Sea under Different Wind Regimes. Physical Oceanography, [e-journal] (6), pp. 12-23. doi:10.22449/1573-160X-2017-6-12-23

22. Kubryakova, E.A., Kubryakov, A.A. and Stanichny, S.V., 2018. Impact of Winter Cooling on Water Vertical Entrainment and Intensity of Phytoplankton Bloom in the Black Sea. Physical Oceanography, [e-journal] 25(3), pp. 191-206. doi:10.22449/1573-160X-2018-3-191-206.

23. Stanev, E.V., Bowman, M.J., Peneva, E.L. and Staneva, J.V., 2003. Control of Black Sea Intermediate Water Mass Formation by Dynamics and Topography: Comparison of Numerical Simulations, Surveys and Satellite Data. Journal of Marine Research, [e-journal] 61(1), pp. 59-99. https://doi.org/10.1357/002224003321586417

${ }^{2}$ Ilyin, Yu., Repetin, L.N., Belokopytov, V., Goryachkin, Yu., Dyakov, N.N., Kubryakov, A. and Stanichny, S., 2012. Hydrometeorological Conditions of the Ukrainian Seas, Vol. 2: The Black Sea. Sevastopol: EKOSI-Gidrofizika, 400 p. (in Russian). 
24. Zatsepin, A.G., Kremenetskiy, V.V., Piotukh, V.B., Poyarkov, S.G., Ratner, Yu.B., Soloviev, D.M., Stanichnaya, R.R., Stanichny, S.V. and Yakubenko, V.G., 2008. Formation of the Coastal Current in the Black Sea Caused by Spatially Inhomogeneous Wind Forcing upon the Upper Quasi-Homogeneous Layer. Oceanology, [e-journal] 48(2), pp. 159-174. https://doi.org/10.1134/S0001437008020021

25. Kubryakov, A.A., Zatsepin, A.G. and Stanichny, S.V., 2019. Anomalous Summer-Autumn Phytoplankton Bloom in 2015 in the Black Sea Caused by Several Strong Wind Events. Journal of Marine Systems, [e-journal] 194, pp. 11-24. https://doi.org/10.1016/j.jmarsys.2019.02.004

26. Tuzhilkin, V.S., 2007. Thermohaline Structure of the Sea. In: A. G. Kostianoy and A. N. Kosarev, eds., 2007. The Black Sea Environment. Berlin; Heidelberg: Springer, pp. 217 253. https://doi.org/10.1007/698_5_077

27. Kara, A.B., Hurlburt, H.E., Wallcraft, A.J. and Bourassa, M.A., 2005. Black Sea Mixed Layer Sensitivity to Various Wind and Thermal Forcing Products on Climatological Time Scales. Journal of Climate, [e-journal] 18(24), pp. 5266-5293. https://doi.org/10.1175/JCLI3573R2.1

28. Birol Kara, A., Helber, R.W., Boyer, T.P. and Elsner, J.B., 2009. Mixed Layer Depth in the Aegean, Marmara, Black and Azov Seas: Part I: General Features. Journal of Marine Systems, [e-journal] 78(suppl.), pp. S169-S180. https://doi.org/10.1016/j.jmarsys.2009.01.022

29. Moiseenko, V.A. and Belokopytov, B.N., 2008. Estimation of Quality of Hydrological Data set Which Have Been Prepared for Solving of Reanalysis Problem of the Black Sea State for 1985-1994. In: MHI, 2008. Ecological Safety of Coastal and Shelf Zones and Comprehensive Use of Shelf Resources. Sevastopol: MHI NANU. Iss. 16, pp. 184-189 (in Russian).

30. Argo Data Management Team, 2019. Argo user's manual V3.3. https://doi.org/10.13155/29825

31. Zatsepin, A.G., Ostrovskii, A.G., Kremenetskiy, V.V., Nizov, S.S., Piotukh, V.B., Soloviev, V.A., Shvoev, D.A., Tsibul'sky, A.L. and Kuklev, S.B. [et al.], 2014. Subsatellite Polygon for Studying Hydrophysical Processes in the Black Sea Shelf-Slope Zone. Izvestiya, Atmospheric and Oceanic Physics, [e-journal] 50(1), pp. 13-25. https://doi.org/10.1134/S0001433813060157

32. Garmashov, A.V., Kubryakov, A.A., Shokurov, M.V., Stanichny, S.V., Toloknov, Yu.N. and Korovushkin, A.I., 2016. Comparing Satellite and Meteorological Data on Wind Velocity over the Black Sea. Izvestiya, Atmospheric and Oceanic Physics, [e-journal] 52(3), pp. 309316. https://doi.org/10.1134/S000143381603004X

33. Kubryakov, A.A. and Stanichny, S.V., 2012. Reconstruction of Mean Dynamic Topography of the Black Sea for Altimetry Measurements. Izvestiya, Atmospheric and Oceanic Physics, [e-journal] 48(9), pp. 973-979. https://doi.org/10.1134/S0001433812090095

34. Oguz, T., Dippner, J.W. and Kaymaz, Z., 2006. Climatic Regulation of the Black Sea HydroMeteorological and Ecological Properties at Interannual-to-Decadal Time Scales. Journal of $\begin{array}{lllll}\text { Marine Systems, } & \text { [e-journal] } & \text { 60(3-4), } & \text { 235-254. }\end{array}$ https://doi.org/10.1016/j.jmarsys.2005.11.011

35. Stanev, E.V., 2015. Understanding Black Sea Dynamics: Overview of Recent Numerical Modeling. Oceanography, [e-journal] 18(2), pp. 56-75. doi:10.5670/oceanog.2005.42

36. Il'in, Yu.P. and Belokopytov, V.N., 2005. Seasonal and Interannual Variability of Gold Intermediate Layer Parameters in the Sevastopol Anticyclone Nearby. In: MHI, 2005. Ecological Safety of Coastal and Shelf Zones and Comprehensive Use of Shelf Resources. Sevastopol: MHI NANU. Iss. 12, pp. 29-41 (in Russian).

37. Akpinar, A., Fach, B.A. and Oguz, T., 2017. Observing the Subsurface Thermal Signature of the Black Sea Cold Intermediate Layer with Argo Profiling Floats. Deep Sea Research Part I: Oceanographic Research Papers, [e-journal] 124, pp. 140-152. https://doi.org/10.1016/j.dsr.2017.04.002

38. Chaigneau, A., Gizolme, A. and Grados, C., 2008. Mesoscale Eddies off Peru in Altimeter Records: Identification Algorithms and Eddy Spatio-Temporal Patterns. Progress in Oceanography, [e-journal] 79(2-4), pp. 106-119. https://doi.org/10.1016/j.pocean.2008.10.013

39. Kubryakov, A.A. and Stanichny, S.V., 2015. Mesoscale Eddies in the Black Sea from Satellite Altimetry Data. Oceanology, [e-journal] 55(1), pp. 56-67. https://doi.org/10.1134/S0001437015010105 
40. Kubryakov, A.A. and Stanichny, S.V., 2015. Seasonal and Interannual Variability of the Black Sea Eddies and Its Dependence on Characteristics of the Large-Scale Circulation. Deep Sea Research Part I: Oceanographic Research Papers, [e-journal] 97, pp. 80-91. https://doi.org/10.1016/j.dsr.2014.12.002

41. Ostrovskii, A.G. and Zatsepin, A.G., 2016. Intense Ventilation of the Black Sea Pycnocline due to Vertical Turbulent Exchange in the Rim Current Area. Deep Sea Research Part I: Oceanographic Research Papers, [e-journal] 116, pp. 1-13. https://doi.org/10.1016/j.dsr.2016.07.011

42. Konovalov, S.K., Murray, J.W. and Luther III, G.W., 2005. Basic Processes of Black Sea Biogeochemistry. Oceanography. [e-journal] 18(2), pp. 24-35. https://doi.org/10.5670/oceanog.2005.39

43. Kubryakov, A., Stanichny, S., Shokurov, M. and Garmashov, A., 2019. Wind Velocity and Wind Curl Variability over the Black Sea from QuikScat and ASCAT Satellite Measurements. Remote Sensing of Environment, [e-journal] 224, pp. 236-258. https://doi.org/10.1016/j.rse.2019.01.034

44. Ovchinnikov, I.M. and Popov, Yu.I., 1987. Cold Intermediate Layer Formation in the Black sea. Oceanology, 27(5), pp. 739-746 (in Russian).

45. Kubryakov, AA. and Stanichny, S.V., 2018. Impact of Vertical Entrainment and Horizontal Dynamics on the Anomalously Strong Coccolithofides Blooms in the Black Sea. Processes in GeoMedia, (3), pp. 70-71 (in Russian).

46. Belokopytov, V.N., 2014. Climatic Variability of the Black Sea Density Structure. Ukrainian Hydrometeorological Journal, (14), pp. 227-235 (in Russian).

47. Belokopytov, V.N. and Shokurova, I.G., 2008. Estimates of Temperature and Salinity Interdecadal Variability in the Black sea during 1951-1955. In: MHI, 2008. Ecological Safety of Coastal and Shelf Zones and Comprehensive Use of Shelf Resources. Sevastopol: MHI NANU. Iss. 12, pp. 12-21 (in Russian).

About the authors:

Arseniy A. Kubryakov - Senior Research Associate, Marine Hydrophysical Institute of RAS (2 Kapitanskaya St., Sevastopol, 299011, Russian Federation), Ph.D. (Phys.-Math.), ORCID ID: 0000-0003-3561-5913, arskubr@mhi-ras.ru

Vladimir N. Belokopytov - Head of Oceanography Department, Marine Hydrophysical Institute of RAS (2 Kapitanskaya St., Sevastopol, 299011, Russian Federation), Dr.Sci. (Geogr.), ORCID ID: 0000-0003-4699-9588, Scopus Author ID: 6602381894, v.belokopytov@ gmail.com

Andrey G. Zatsepin - Head of Laboratory, Shirshov Institute of Oceanology of RAS (5 Nakhimovskiy Avenue, 117997, Russian Federation), Dr.Sci. (Phys.-Math.), ORCID ID: 0000-0002-5527-5234, zatsepin@ ocean.ru

Sergey V. Stanichny - Senior Research Associate, Head of Remote Sensing Department, Marine Hydrophysical Institute of RAS (2 Kapitanskaya St., Sevastopol, 299011, Russian Federation), Ph.D. (Phys.-Math.), stanichny@mhi-ras.ru

About the authors:

Arseniy A. Kubryakov - calculation and analysis of spatio-temporal variability of the MLD thickness, determination of its relationship with the characteristics of eddies, analysis of changes in the stratification

Vladimir N. Belokopytov - preparation of a historical array of hydrological data, participation in the formulation of conclusions

Andrey G. Zatsepin - preparation of data from "Aqualog" anchored profiler, analysis of the relationship between the MLD thickness and wind

Sergey V. Stanichny - analysis of satellite information about the velocity of current, analysis of the relationship between the MLD thickness and dynamic characteristics

Vladimir B. Piotukh - preparation and processing of hydrological data arrays on the measurements of "Aquanaut" ship voyages

All the authors have read and approved the final manuscript.

The authors declare that they have no conflict of interest. 